\title{
DEATH AT THE WORKPLACE IN THE PLEVEN DISTRICT FOR A PERIOD OF 10 YEARS (STUDY, BASED ON THE FORENSIC MEDICINE ARCHIVE REPORTS AND PRESENTATION OF TWO CASES OF LABOR ACCIDENTS)
}

\author{
D. Dekov $^{1 *}$, I. Stoilova ${ }^{2}$, I. Veleva ${ }^{2}$ \\ ${ }^{1}$ Department of General and Forensic Medicine and Deontology, Faculty of Public Health, \\ Medical University - Pleven, Bulgaria \\ ${ }^{2}$ Department of Hygiene, Medical Ecology, Occupational Diseases and Disaster Medicine, \\ Faculty of Public Health, Medical University - Pleven, Bulgaria \\ ${ }^{3}$ Department of Psychiatry and Medical Psychology, Faculty of Public Health, \\ Medical University - Pleven, Bulgaria
}

\begin{abstract}
The objective of this study is the dynamics, structure, number, type, character and causes of death of persons, who have died at their workplace in the district of Pleven.

Using statistical-descriptive and archival-documentary methods of investigation, 53 forensic medical expertise for the study of a corpse from the archives of the Department of Forensic Medicine of the Medical University of Pleven for the period from 2008 to 2017 years were investigated. 18 cases of sudden cardiac death, 33 cases of death from occupational accidents and 2 cases of suicide in the workplace have been identified.

The ratio of males to females is 9.6: 1 . The ratio of urban to rural population is 3: 1 . The highest mortality rate is between the ages of 41 and 50 (15 cases or 28\%), with the age groups 51-60 and 61-70 being the second most frequent.

The most common causes of death are mechanical trauma, followed by asphyxia. Approximately half of the mechanical trauma cases are a fall from a height during construction works.

According to the days of the week most frequent the incidents happen on Monday, and according to the month of the year - in May and July.

Two interesting expert cases of death from an accident at the workplace were also presented.
\end{abstract}

Key words: labor accident, death at the workplace, causes of death.

\section{INTRODUCTION}

Occupational accident is any sudden damage to health occurring during and in connection with or in connection with the work performed, as well as any work done in the interest of the enterprise when it caused incapacity to work or death (1).

Occupational accident is also any accident occurred during the usual way of going to or returning from the workplace to the main place of residence of the individual; the place where the insured worker usually has a meal during the working day; the place of receipt of the wage $(1,2)$.

\footnotetext{
*Correspondence to: Dekov D. P

(drdekov@abv.bg), Faculty of Public Health, Medical University - Pleven, 1, Kliment Ohridski str, 5800 Pleven, Republic of Bulgaria
}

There is no occupational accident when the injured has deliberately harmed his or her health.

The legislation on accidents at the workplace and occupational diseases is part of the Social Security Code, the Labor Code, the Health and Safety at Work Act, the Regulation on the Establishment, Investigation, Registration and Reporting of Accidents at Work and the Ordinance on the Procedure for Reporting, registering, validation, appeal and reporting of occupational diseases $(1,3)$.

The occurred occupational accident is declared at the Territorial Division of the National Social Security Institute (TD at NSSI) within 3 working days of the occurrence of the accident. For each accident, an investigation by the Commission under the responsibility of the TD 
of the NSSI and the mandatory participation of representatives of the Executive Labor Inspectorate (IA), the Labor Inspectorate (GLP), the labor committees or working groups and other competent bodies are carried out.

The employer keeps a register of occupational accidents. In the TD of the NSSI accident files are compiled and a register is kept. The control over compliance with the normative requirements for accidents at work is carried out by the control bodies of NSSI. The control for provision of healthy and safe working conditions and the measures taken to prevent and reduce accidents at work are carried out by the control bodies of EA GIT $(3,4)$.

According to data from the National Statistical Institute, in the recent years labor accidents in the country have steadily increased in number. In 2016, 2848 incidents were reported at the workplace. Leading professions are:

- Drivers - 187 incidents

- Salespersons and distributors - 162 incidents

- Doctors and nurses -156 incidents

Of the above, 88 cases of death at the workplace were recorded. Most deaths were recorded in the Ground Transport sector and the Construction sector (5). These incidents also affect the most reliable measure of the
DEKOV D., et al. global burden of illness, such as the DALYs indicator (Disability-Adjusted Life Years)" (6).

\section{PURPOSE AND OBJECTIVES}

To examine the number, dynamics, structure, type, character and causes of death of persons who died at their workplace in the Pleven region. To investigate the distribution by gender, age groups, place of residence of the deceased, the forensic genus of death, the type of external factors most frequently acted as well as other signs.

\section{MATERIAL AND METHODS}

The forensic examinations for the examination of a corpse from the archives of the Department of Forensic Medicine of the Medical University of Pleven for the period 2008-2017 have been investigated. All cases were investigated by the Prosecutor's Office of the Republic of Bulgaria and the experts were appointed by an investigator's decree, according to the Criminal Procedure Code (PPC). Statistical-descriptive and archivaldocumentary research methods were used.

\section{RESULTS}

During the research period, 53 cases of people who died in the workplace were identified. They account for $2.8 \%$ of all autopsies and forensic autopsy (Table 1).

Table 1. Distribution of death at the workplace cases by years

\begin{tabular}{|l|l|l|l|l|l|l|l|l|l|}
\hline 2008 & 2009 & 2010 & 2011 & 2012 & 2013 & 2014 & 2015 & 2016 & 2017 \\
\hline 9 & 6 & 3 & 7 & 6 & 1 & 5 & 6 & 5 & 5 \\
\hline
\end{tabular}

In 18 of the cases, or $34 \%$ the cause of death is a disease, predominantly cardiovascular (sudden cardiac death). The remaining 35 cases, or $66 \%$, are result of a violent death. 33 of them are accidents, such as accidents at work in the narrow sense of the word. There are also two cases of suicide at the workplace, one by hanging and the other by fire injury. Cases of forced death at work (35) also account for $2.8 \%$ of all cases of violent death in the region for the period.

By gender, the deceased are distributed as follows: 48 (or 91\%) male and 5 (or 9\%) are female. The ratio of males to females is 9.6: 1 . In $39(74 \%)$ cases, the deceased were from the town and the remaining $14(26 \%)$ were rural residents. The ratio between urban and rural residents is approximately 3 : 1 (Tables $\mathbf{2 , 3 , 4}$ ).

Table 2. Age distribution of death at the workplace cases

\begin{tabular}{|l|l|}
\hline Up to 20 years & 1 \\
\hline From 21 to 30 years & 4 \\
\hline From 31 to 40 years & 8 \\
\hline From 41 to 50 years & 15 \\
\hline From 51 to 60 years & 12 \\
\hline From 61 to 70 years & 12 \\
\hline Over 70 years & 1 \\
\hline
\end{tabular}

Table 3. Causes of violent death structure

\begin{tabular}{|l|l|}
\hline Mechanical trauma & 22 \\
\hline Thermal trauma & 1 \\
\hline Asphyxia & 6 \\
\hline Sulfur dioxide poisoning & 1 case with 2 deceased workers \\
\hline Electrocution & 3 \\
\hline Cardiac arrest as a result of histamine shock & 1 \\
\hline
\end{tabular}


Table 4. Type of mechanical trauma as most common cause of death

DEKOV D., et al.

\begin{tabular}{|l|l|}
\hline Automotive Trauma (Truck Drivers) & 3 \\
\hline Accidents with lifting and agricultural machinery & 3 \\
\hline Fall from height (construction sites) & 11 \\
\hline Other blunt and sharp injuries in production & 3 \\
\hline Explosive injury (manufacturing) & 1 \\
\hline Gunshot Trauma (Suicide) & 1 \\
\hline
\end{tabular}

The cases of asphyxia, as second cause of death are the following: 1 case of suicide, 1 case of aspiration asphyxia of a worker, who fell in a grain dryer container and 4 cases of compression asphyxia in workers buried in excavation site.
In five of the cases $(9.4 \%)$ in the blood of the deceased in the workplace, an alcohol content higher than 0.5 promiles was found.

The distribution of fatalities in the workplace according to the months of the year shows the highest number in May and July (eight for each) and the lowest in December (one case)

(Table 5).

Table 5. Distribution of death at the workplace cases according to the days of the week

\begin{tabular}{|c|c|c|c|c|c|c|c|}
\hline Monday & Tuesday & Wednesday & Thursday & Friday & Saturday & Sunday & Total \\
\hline 13 & 8 & 12 & 4 & 8 & 3 & 5 & 53 \\
\hline
\end{tabular}

\section{DISCUSSION}

The Pleven region covers the central part of the Danube Plain and part of the Prebalkan. It has borders with the districts of Vratsa, Lovech and Veliko Tarnovo and to the north with the Danube River. It has an area of $4,337 \mathrm{~km} 2$ and a population of 248,138 people (December 31 , 2016). In the recent past, the area had welldeveloped light and heavy industry, as well as agricultural production. At present, most of the industrial enterprises are closed down and the population has been decreasing in recent years. The most were the deaths in 2008-9, and the least in 2013-1. The average for the period is 5.3. In recent years there has been some "stabilization" around the average.

One third of these cases involve sudden cardiac death in the workplace. For the remaining two thirds we have a violent death case. The causes of the two suicides have not been clarified, but there has been an increase in worldwide cases of bullying in the workplace (7).

The higher mortality rate for men is associated with significantly higher risk associated with the professional activities they exercise.

According to the analysis of causes of death and the structure of mechanical injuries in 15 cases (nearly half), it is a case of construction incidents.

It is alarming that in $9.4 \%$ of cases there is alcohol in the blood of the deceased. This has inevitably played a role in the incident. Increased control by employers is needed in this area.
The mortality curve for the months of the year is varied. The low levels in the winter months are explained by the lack of intensive construction activities in that period.

Case analysis according to weekdays shows that the most risky day is Monday, followed by Wednesday.

We present two rare expert cases from the practice of one of the authors:

First case: This is a 57-year-old man, the company where he worked was hired in January to destroy the building and clear the terrain of the former fodder factory. During work, the worker suddenly slides over an icy slope of concrete and falls into a deep concrete bunker filled with stagnant dirty cold water and pieces of styrofoam. The rescue teams extracted him deceased. During the autopsy, massive abrasions on the face and upper limbs picture a rapid death (cerebral and pulmonary edema, punctual pleural effusions, acute venous stagnation and intense pink carcass spots) were found. There are no signs of drowning or overcooling.

A "heart arrest" (sudden cardiac death, sudden death in water) was accepted as the cause of death. It is stated that the leading factor in the genesis of death is the histamine shock, triggering a reflex spasm of the blood vessels from the sudden irritation of the skin receptors in the cold water, as well as the psychoemotional stress. In the case of the abovementioned cause of death, the insurance company initially refused to pay compensation for the life insurance, assuming it was "heart attack death" as a result of existing illness. In the court case, forensic expertise clarified in 
detail the cause and the genesis of death and the court accepted that it is "heart attack death" as a result of trauma that arose during work. Following the court's decision, the insurance company paid the corresponding compensation to the deceased's relatives. The case is presented as an example of the importance of a precise forensic medical judgment.

Second case: A 43-year-old man worked as a combine harvester operator, harvesting sunflower in September. At dusk, he was found by the driver of the truck carrying the sunflower dead, fallen under the "header" of a combine harvester, with the legs cut off. The autopsy revealed paleness (anemia) of the internal organs and carcass spots, complete amputation of the legs of both legs at a height of $50 \mathrm{~cm}$ from the heel, Minakov stains under the inner envelope of the heart (endocardium), alcohol content in the blood 2.4 and in the urine 3.2 promiles.

As a cause of death, acute blood loss and shock have been reported as a result of haemorrhage from the high blood vessels of the amputated lower limbs.

The amputations of both legs are at a height of $50 \mathrm{~cm}$ from the heels, which exactly corresponds to the height of the cutting knives of the combine header.

It is stated that the concentration of alcohol in the blood is at the upper limit of the average degree of alcoholic absorption and the concentration of alcohol in the urine within the range of severe alcoholic absorption. Due to severe disturbances in wisdom, attention, coordination of movements, equilibrium and highly delayed reactions, alcohol undoubtedly played a leading role in the incident.
The case is presented as an example of irresponsible behavior for both the worker himself and his employer.

\section{CONCLUSION}

Cases of death at work cover $2.8 \%$ of all forensic autopsy cases and $2.8 \%$ of all cases of violent death. The most affected is the age group between 41 and 50 years. The male / female ratio is 9.6: 1 . The greatest number of cases is in construction work. The incidence rate is the highest in May and July, and the most dangerous day of the week is Monday.

\section{REFERENCES}

1. Social insurance code, State Gazette, issue 67, (in Bulgarian), 2003.

2. Sredkova $\mathrm{K}$ et al. Healthy and Safe working conditions, Trud i Pravo, Sofia, p. 48-53 (in Bulgarian), 2006.

3. Ordinance for establishement, investigation, registration and reporting industrial accidents, State Gazette, issue 6, (in Bulgarian), 2000.

4. Donev, G, K. Petkova, I Kokalov Manual Safety and Health in working conditions at a factory, Trud i Pravo, Sofia, p. 295-306 (in Bulgarian), 2009.

5. http://www.noi.bg/aboutbg/st/statistic/304tzpb/infotz

6. Grancharova, G. M. Kamburova, S. Georgieva, S. Alexandrova- Yankulovska, D. Tsanova Dynamics of causes and risk factors of global burden of diseases (1990 - 2015), Social medicine, No 1, p. 7-9 (in Bulgarian), 2017.

7. https://www.blitz.bg/.../analizatori-biyattrevoga-globalizatsiyata-nosi-vina-zasamoubiys 